\title{
Comparative Analysis of Strengthening with Respect to Microstructural Evolution for 0.2 Carbon DP, TRIP, Q\&P Steels
}

\author{
Jong-Won Jin, Yeong-Do Park*, Dae-Geun Nam**, Seung Bok Lee***, Sung Il Kim***, \\ Namhyun Kang ${ }^{\dagger}$ and Kyung-mox Cho \\ Department of Materials Science and Engineering, Pusan National University, Busan 609-735, Korea \\ *Department of Advanced Materials Engeering, Dong-Eui University, Busan 341-714, Korea \\ **Dongnam Technology Service Division, Korea Institute of Industrial Technology, Busan 618-230, Korea \\ ***Technical Research Laboratories, POSCO, Kwangyang 545-090, Korea
}

(Received May 15, 2009 : Received in revised form May 25, 2009 : Accepted May 25, 2009)

\begin{abstract}
The microstructures and mechanical properties of Dual Phase (DP), Transformation-Induced Plasticity (TRIP), and Quenching \& Partitioning (Q\&P) steels were investigated in order to define the strengthening mechanism of $0.2 \mathrm{C}$ steel. An intercritical annealing between Ac1 and Ac3 was conducted to produce DP and TRIP steel, followed by quenching the DP and TRIP steel being quenched at to room temperature and by the TRIP steel being austemperingaustempered-air cooling cooled the steel toat room temperature, respectively. The $\mathrm{Q} \& \mathrm{P}$ steel was produced from full austenization, followed by quenching to the temperature between $\mathrm{M}_{\mathrm{s}}$ and $\mathrm{M}_{\mathrm{f}}$, and then enriching the carbon to stabilize the austenite throughout the heat treatment. For the DP and TRIP steels, as the intercritical annealing temperature increased, the tensile strength increased and the elongation decreased. The strength variation was due to the amount of hard phases, i.e., martensite and bainite, respectively in the DP and TRIP steels. It was also found that the elongation also decreased with the amount of soft ferrite in the DP and TRIP steels and with the amount of the that was retained in the austenite phasein the TRIP steel, respectively for the DP and TRIP steels. For the Q\&P steel, as the partitioning time increased, the elongation and the tensile strength increased slightly. This was due to the stabilized austenite that was enriched with carbon, even when the amount of retained austenite decreased as the partitioning time increased from 30 seconds to 100 seconds.
\end{abstract}

Key words DP steel, TRIP steel, Q\&P Steel, retained austenite, carbon partitioning.

\section{Introduction}

Dual phase (DP) steels have been used for high strength sheet steel, in which high strength is obtained by the high volume fraction of martensite with sacrificing elongation. Consequently, poor press formability restricts the application for automotive sheet steels. ${ }^{1)}$ To improve these problems, transformation-induced plasticity (TRIP) steels gained an interest in advanced high strength steels (AHSS). They allow high strength and ductility as well as formability. ${ }^{2)}$ But, tensile strength for the TRIP steel is lower than that for the DP steel. Recently, the automotive sheet steels demand for high strength (tensile strength $>$ $1000 \mathrm{Mpa}$ ) and ductility (total elongation $\approx 20 \%$ ). For the reason, an investigation of quenching and partitioning (Q\&P) steels is underway to satisfy the demands. The Q\&P steel is

Corresponding author

E-Mail : nhkang@pusan.ac.kr (N. H. Kang) normally composed of carbon-depleted martensite and carbonenriched retained austenite post to full austenization.

The main mechanism for Q\&P steel is carbon partitioning to untransformed austenite from carbon supersaturated martensite during the partitioning process after initial quenching to a temperature between martensite-start $\left(\mathrm{M}_{\mathrm{s}}\right)$ and martensite finish $\left(\mathrm{M}_{\mathrm{f}}\right)$ temperatures. ${ }^{3)}$ Consequently, the Q\&P steel exhibits transformation-induced plasticity properties by the stabilized austenite and hard properties of martensite. Specifically, volume fraction and stability of carbon-enriched and stabilized austenite have been incorporated to understand the strength and elongation relationship. $^{3-4)}$ The volume fraction of retained austenite normally decreases as partitioning time and temperature increase. The reasons include the probable interaction of competing reactions that have either carbide precipitation despite of $\mathrm{Si}$ added to suppress carbide precipitation or bainite transformation of the austenite during the partitioning treatment. The elongation often increased 
despite the decrease of the retained austenite volume fraction, and it was understood because the stability of retained austenite increased. ${ }^{5 \sim 6)}$ However, the competing reaction between the stability and the volume fraction of the retained austenite is not clear to understand the tensile properties. This study will discuss the microstructural features to correlate the strength and ductility. Different conditions of heat treatment were applied to produce DP, TRIP, and Q\&P. Specially, the influence of carbon partitioning was studied on the variation of the volume fraction and stability of retained austenite.

\section{Experimental Procedure}

Cold-rolled low alloy TRIP steel sheet was used for study. Chemical composition of the steel is Fe-0.2C-1.48Si1.5Mn (wt.\%). Tensile testing samples (ASTM A 370-05, sub-size) were machined from sheet steel, followed by the heat treatment. The heat treatment conditions for DP, TRIP, Q\&P steels are shown in Table 1. Heat treatment conditions were selected through Ac1, Ac3, and $M_{s}$ temperatures which were estimated from the available equations ${ }^{7 \sim 8)}$.

$$
\begin{aligned}
& \operatorname{Ac} 1\left({ }^{\circ} \mathrm{C}\right)=723-10.7 \mathrm{Mn}+29.1 \mathrm{Si}=760^{\circ} \mathrm{C} \\
& \operatorname{Ac} 3\left({ }^{\circ} \mathrm{C}\right)=910-203\left(\mathrm{C}^{1 / 2}\right)+44.7 \mathrm{Si}=885^{\circ} \mathrm{C} \\
& \mathrm{M}_{\mathrm{s}}\left({ }^{\circ} \mathrm{C}\right)=539-423 \mathrm{C}-30.4 \mathrm{Mn}-7.5 \mathrm{Si}+30 \mathrm{Al}=398^{\circ} \mathrm{C}
\end{aligned}
$$

Phase fraction $(\alpha: \gamma)$ at intercritical annealing temperature determines the final microstructures and mechanical properties for DP steels. ${ }^{9)}$ Therefore, DP steels were produced by the intercritical annealing $\left(860{ }^{\circ} \mathrm{C}, 820^{\circ} \mathrm{C}\right.$,
$780{ }^{\circ} \mathrm{C}$ ) for 5 minutes, followed by water quenching to room temperature. Intercritical annealing temperature, isothermal treatment temperature and time are essential to optimize mechanical property with respect to retained austenite formation in TRIP steels. ${ }^{10)}$ Therefore, TRIP steels were intercritically annealed to form ferrite and austenite at a temperature between Ac1 and Ac3 for 5minutes. And, the sample was quenched to the temperature above Ms, austempered at $430{ }^{\circ} \mathrm{C}$ for $3 \mathrm{~min}$, and air cooled to room temperature. Mechanical properties and retained austenite formation of the Q\&P steel were studied with respect to partitioning time. Therefore Q\&P steel was fully austenized at $920^{\circ} \mathrm{C}$ for $5 \mathrm{~min}$, followed by quenching to a temperature between $\mathrm{M}_{\mathrm{s}}$ and $\mathrm{M}_{\mathrm{f}}$, and then enriching carbon to stabilize the austenite through the partitioning $30 \mathrm{~s} \sim 100 \mathrm{~s}$, and finally quenching to room temperature. Tensile specimens (length: $100 \mathrm{~mm}$, gauge length: $25 \mathrm{~mm}$, and thickness: $1.1 \mathrm{~mm}$ ) were heated with respect to the DP, TRIP, and Q\&P process. Two tensile tests were conducted for each condition with a crosshead speed of $2 \mathrm{~mm} / \mathrm{min}$ at room temperature.

DP steels were etched with $2 \%$ nital. And, TRIP and Q\&P steels were etched with $2 \%$ nital and sodium metabisulfite $\left(\mathrm{Na}_{2} \mathrm{~S}_{2} \mathrm{O}_{5}+\mathrm{H}_{2} \mathrm{O} 100 \mathrm{ml}\right) .{ }^{11)}$ The volume fractions of the constituents in DP steels were measured by the image analyzing software. DP steels were simply composed of martensite and ferrite. However, the observation of the retained austenite was difficult by optical microscopy for TRIP and Q\&P steels. Therefore, saturation magnetic measurement was used for the determination of the amount of retained austenite. Volume

\begin{tabular}{|c|c|c|c|c|}
\hline \multirow{2}{*}{ DP } & \multicolumn{2}{|c|}{$\begin{array}{l}\text { Intercritical } \\
\text { annealing } \\
\text { temperature }\end{array}$} & \multicolumn{2}{|c|}{$\begin{array}{c}\text { Intercritical } \\
\text { annealing } \\
\text { Time }\end{array}$} \\
\hline & \multicolumn{2}{|c|}{$\begin{array}{l}860{ }^{\circ} \mathrm{C} \\
820{ }^{\circ} \mathrm{C} \\
780{ }^{\circ} \mathrm{C}\end{array}$} & \multicolumn{2}{|c|}{$\begin{array}{l}5 \mathrm{~min} \\
5 \mathrm{~min} \\
5 \mathrm{~min}\end{array}$} \\
\hline \multirow{2}{*}{ TRIP } & $\begin{array}{l}\text { Intercritical } \\
\text { annealing } \\
\text { temperature }\end{array}$ & $\begin{array}{c}\text { Intercritical } \\
\text { annealing } \\
\text { time }\end{array}$ & $\begin{array}{l}\text { Isothermal } \\
\text { treatment } \\
\text { temperature }\end{array}$ & $\begin{array}{c}\text { Isothermal } \\
\text { treatment } \\
\text { time }\end{array}$ \\
\hline & $\begin{array}{l}860^{\circ} \mathrm{C} \\
820^{\circ} \mathrm{C} \\
780^{\circ} \mathrm{C}\end{array}$ & $\begin{array}{l}5 \mathrm{~min} \\
5 \mathrm{~min} \\
5 \mathrm{~min}\end{array}$ & $\begin{array}{l}430{ }^{\circ} \mathrm{C} \\
430{ }^{\circ} \mathrm{C} \\
430{ }^{\circ} \mathrm{C}\end{array}$ & $\begin{array}{l}3 \mathrm{~min} \\
3 \mathrm{~min} \\
3 \mathrm{~min}\end{array}$ \\
\hline \multirow{2}{*}{ Q\&P } & $\begin{array}{c}\text { Full } \\
\text { austenitization }\end{array}$ & Quenching & $\begin{array}{l}\text { Partitioning } \\
\text { temperature }\end{array}$ & $\begin{array}{l}\text { Partitioning } \\
\text { time }\end{array}$ \\
\hline & $\begin{array}{l}920^{\circ} \mathrm{C} \\
920^{\circ} \mathrm{C}\end{array}$ & $\begin{array}{l}240{ }^{\circ} \mathrm{C}, 10 \mathrm{~s} \\
240^{\circ} \mathrm{C}, 10 \mathrm{~s}\end{array}$ & $\begin{array}{l}350{ }^{\circ} \mathrm{C} \\
350{ }^{\circ} \mathrm{C}\end{array}$ & $\begin{array}{l}30 \mathrm{~s} \\
100 \mathrm{~s}\end{array}$ \\
\hline
\end{tabular}
fraction of retained austenite were measured through

Table 1. Heat treatment conditions of the cold-rolled steel sheet. 
classification of magnetism materials such as BCC (ferrite) and $\mathrm{BCT}$ (martensite) constructions and non-magnetism material like FCC (austenite) construction from specimens (length: $10 \mathrm{~mm}$, width: 3 4 mm). Generally, austenite volume fractions were determined by using $\mathrm{x}$-ray diffraction (XRD) in the TRIP and Q\&P steels. ${ }^{12)}$ Therefore, molybdenum radiation was used in this study to verify the result of saturation magnetic measurement. Retained austenite peaks were easily observed for the TRIP steel while only (220) austenite peak was obtained for the Q\&P steel. The austenite carbon content of the austenite was estimated from the austenite (220) position (determined from peak fitting software) using the following equation ${ }^{12 \sim 13)}$.

$$
\mathrm{a}_{0}(\AA)=3.5467+0.0467 \mathrm{C}(\text { wt.\%) }
$$

where $\mathrm{a}_{0}$ is a lattice parameter of austenite in angstroms and $\mathrm{C}$ is carbon content in weight percent. The $\mathrm{K}_{\alpha}$ wavelength was used to calculate (220) austenite peak position.

\section{Results and discussion}

\subsection{Microstructural evolution}

Microstructures of cold rolled sheets were composed of ferrite and pearlite with band morphology. The band morphology was disappeared by heat treatment. Microstructures of DP steel are shown in Fig. 1. DP steels were composed of ferrite (light gray) and martensite (dark gray and black). Fine structure of ferrite and smaller ferrite volume was achieved as the intercritical annealing temperature was increased. This was because more austenite was formed at higher intercritical annealing temperature and the austenite was transformed to martensite during quenching.

Microstructures of TRIP steels are shown in Fig. 2. as a function of intercritical annealing temperatures. TRIP steels are composed of ferrite (brown), bainite (black), and retained austenite (white). Initial austenite at an intercritical annealing temperature was transformed to bainite by isothermal treatment. Fine structure of ferrite and smaller ferrite volume was achieved with higher intercritical annealing temperature. This was because less ferrite was formed at the higher intercritical annealing temperature.

Microstructures of Q\&P steel are shown in Fig. 3. as a function of partitioning time. Q\&P steel was composed of carbon-depleted martensite (brown and black) and carbon -enriched retained austenite (white). Microstructural evolution for the Q\&P steel varied because of carbon diffusion from carbon supersaturated martensite to untransformed austenite during the partitioning process. Microstructural

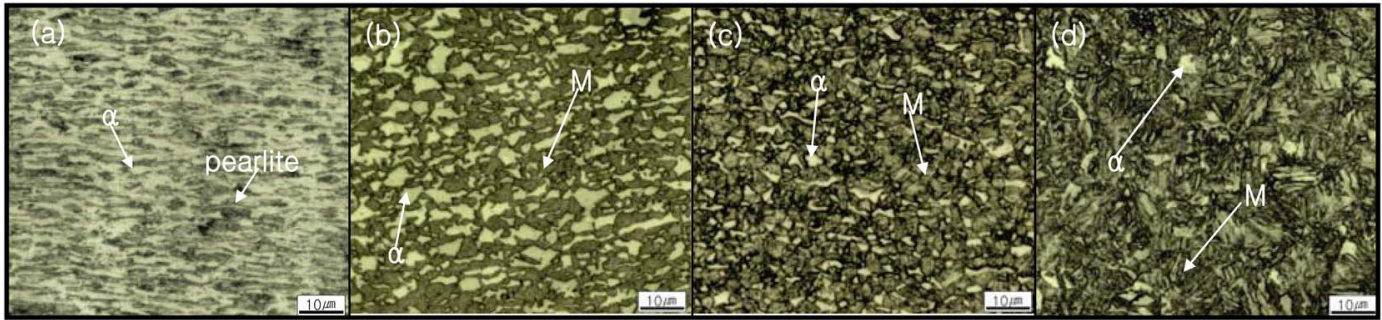

(a) (c) (d)

Fig. 1. Microstructure of (a) the as rolled DP steel and annealed DP steel at (b) $780{ }^{\circ} \mathrm{C}$, (c) $820^{\circ} \mathrm{C}$, (d) $860{ }^{\circ} \mathrm{C}$ for $5 \mathrm{~min}$, followed by water quenching to room temperature.

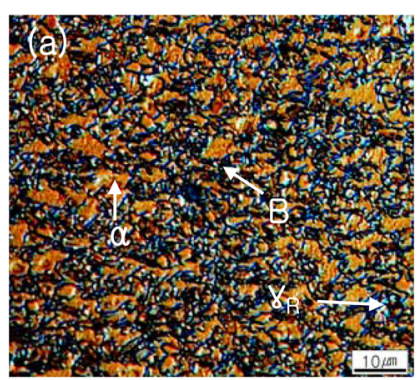

(a)

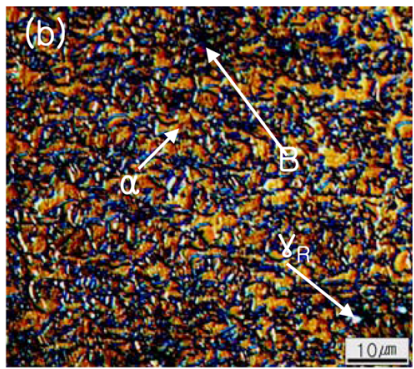

(b)

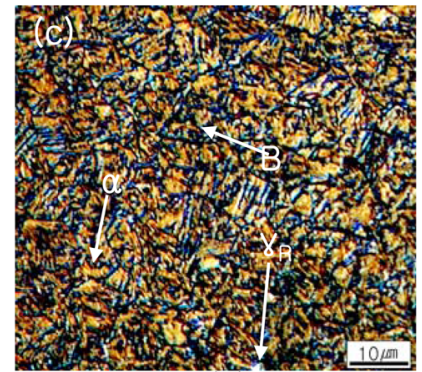

(c)

Fig. 2. Microstructure of the TRIP steel annealed at (a) $780{ }^{\circ} \mathrm{C}$, (b) $820{ }^{\circ} \mathrm{C}$, (c) $860{ }^{\circ} \mathrm{C}$ for $5 \mathrm{~min}$, followed by isothermal treatment at $430{ }^{\circ} \mathrm{C}$ for $3 \mathrm{~min}$, and then air cooling to room temperature. 


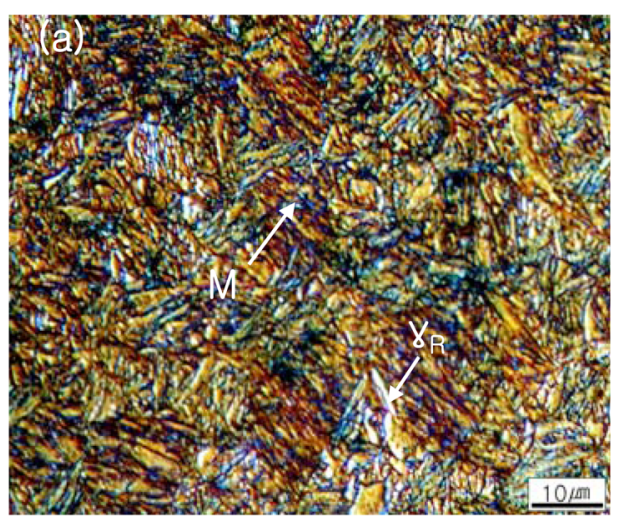

(a)

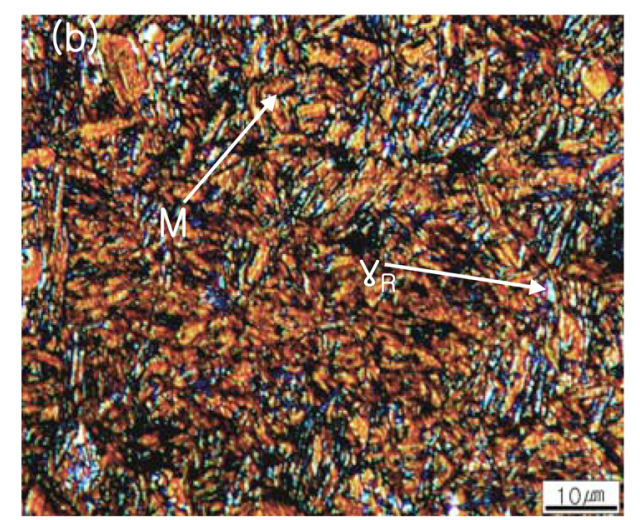

(b)

Fig. 3. Microstructure of the Q\&P steel annealed at $920{ }^{\circ} \mathrm{C}$ for $5 \mathrm{~min}$ and quenched to $240{ }^{\circ} \mathrm{C}$, followed by partitioning at $350{ }^{\circ} \mathrm{C}$ for (a) $30 \mathrm{~s}$ and (b) $100 \mathrm{~s}$, and then water quenching.
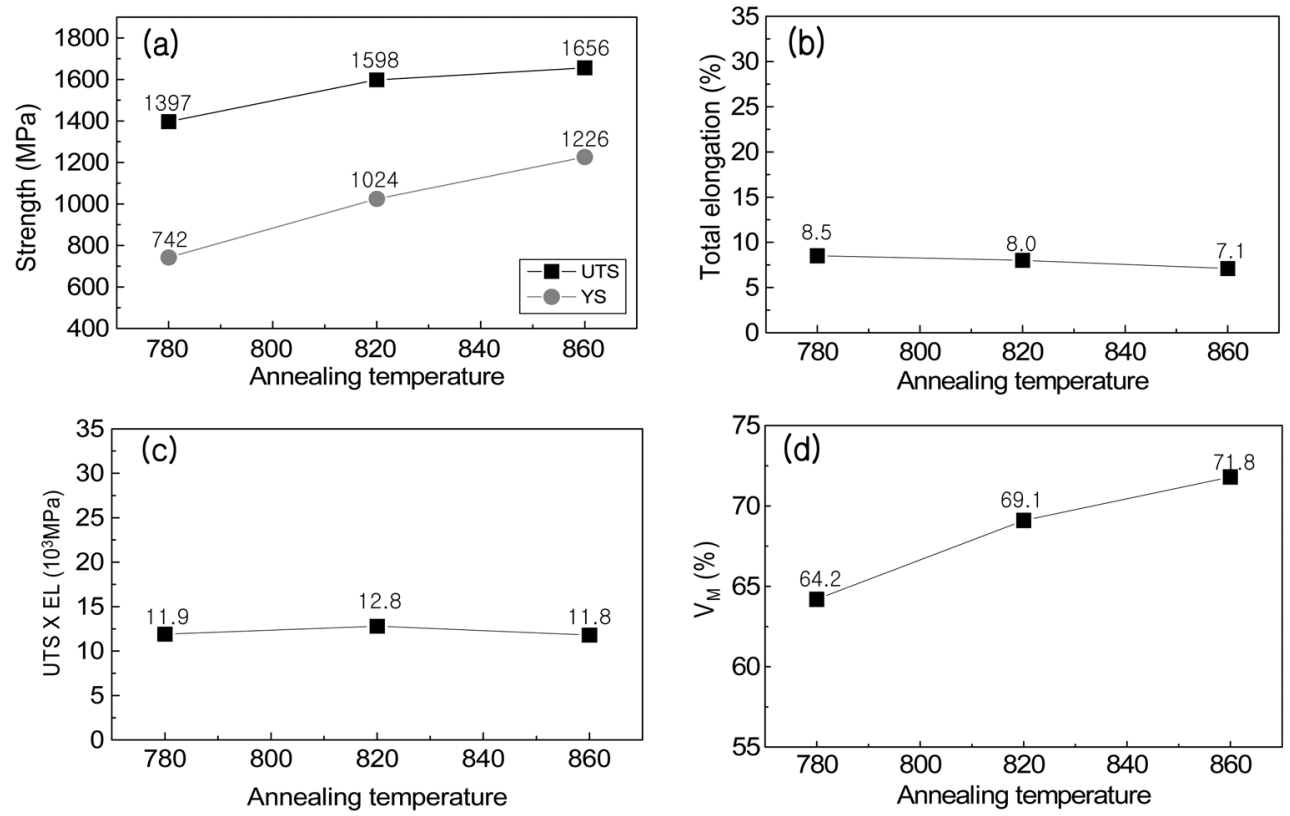

Fig. 4. Tensile properties and martensite volume fraction of the DP steels intercritically annealed at $780{ }^{\circ} \mathrm{C}, 820^{\circ} \mathrm{C}$ and $860{ }^{\circ} \mathrm{C}$; (a) tensile strength and yield strength, (b) total elongation, (c) UTS X EL combination, (d) volume fraction of martensite.

changes as a function of partitioning time were difficult to distinguish. The microstructures were mostly the same for $30 \mathrm{~s}$ and $100 \mathrm{~s}$. However, the retained austenite should be stabilized more significantly because the retained austenite is enriched with more carbon, as the partitioning time is increased. Detailed explanation on the carbon enrichment will be discussed in the following section 3. 2 .

\subsection{Mechanical properties}

Mechanical properties and martensite volume fraction of DP steel are shown in Fig. 4. as a function of intercritical annealing temperature. Larger volume fraction of martensite was observed for the higher intercritical annealing temperature, increasing the ultimate tensile strength (UTS) and the yield strength (YS) with the intercretical annealing temperature. However, total elongation decreased with a ferrite volume fraction as the annealing temperature increased. The combination value (UTS X EL) was not significantly changed with respect to the annealing temperature. Tensile strength was influenced by martensite amount and ductility was by ferrite amount in DP steel. For the study, the volume fraction of martensite and strength were larger than the usual level of low carbon DP steel $(<0.1 w t . \% \mathrm{C})$. It is speculated that the reasons 

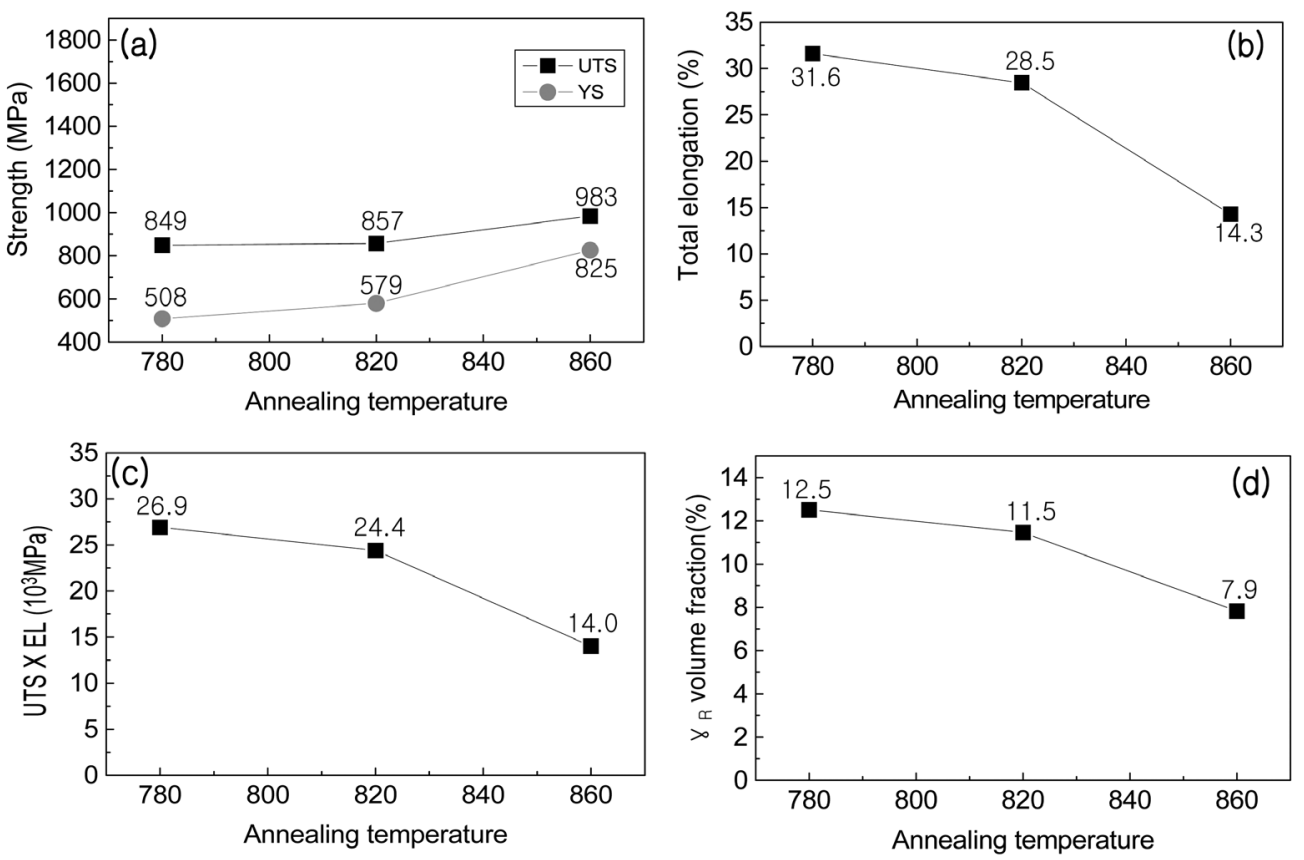

Fig. 5. Tensile properties and retained austenite volume fraction of the TRIP steels annealed at $780{ }^{\circ} \mathrm{C}, 820{ }^{\circ} \mathrm{C}$ and $860{ }^{\circ} \mathrm{C}$; (a) tensile strength and yield strength, (b) total elongation, (c) UTS X EL combination, (d) volume fraction of retained austenite.

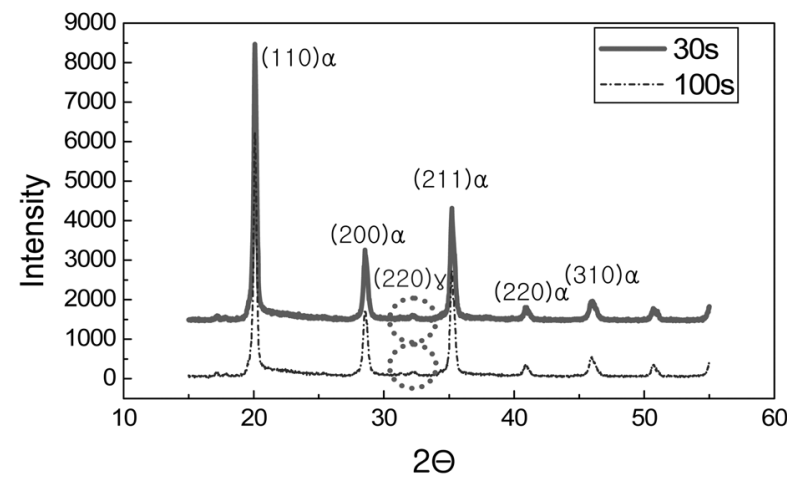

Fig. 6. XRD spectrums of the Q\&P steels partitioning for 30 s and $100 \mathrm{~s}$ (Mo-K $\alpha$ radiation).

are occurred through the high carbon contents for the steels in the study.

Fig. 5. shows mechanical properties and volume fraction of retained austenite in TRIP steel. As the intercritical annealing temperature increased, the prior austenite volume fraction increased, therefore carbon contents of austenite and stability of austenite decreasing, and finally the volume fraction of retained austenite decreasing. For the reason, transformation from austenite to bainite was increased during isothermal treatment, and the larger strength was obtained as the bainite amount was increased. Elongation decreased for the high intercritical temperature because the retained austenite and ferrite volume fraction decreased. Comparing TRIP steel with DP steel as a function of intercritical annealing temperature, the large elongation for TRIP steel was observed due to the formation of retained austenite. As the annealing temperature increased, the increase of tensile strength was not so significant as compared to the decrease of elongation. Therefore, the combination value (UTS X EL) decreased consistently as the annealing temperature increased. By the way, the combination value (UTS X EL) for TRIP steel was larger than that for DP steel.

Fig. 6. shows a result of XRD (Mo- $\mathrm{K}_{\alpha}$ radiation) measurement of Q\&P steel. The one peak for retained austenite was obtained and carbon content in the austenite was estimated from the austenite (220) peak position. All of the retained austenite peaks were obtained for TRIP steel, e.g., (111), (200), and (220). The authors speculate that the reasons are due to the small volume fraction of retained austenite or a different size/ morphology/distribution of retained austenite.

Fig. 7. shows tensile properties and retained austenite characterization of Q\&P steel. As the partitioning time increased, the UTS, YS and TE increased while volume fraction of retained austenite decreased. Therefore, the combination value (UTS XEL) should increase with time. These results are not satisfy that the automotive sheet steels demand for high strength (tensile strength $>$ 

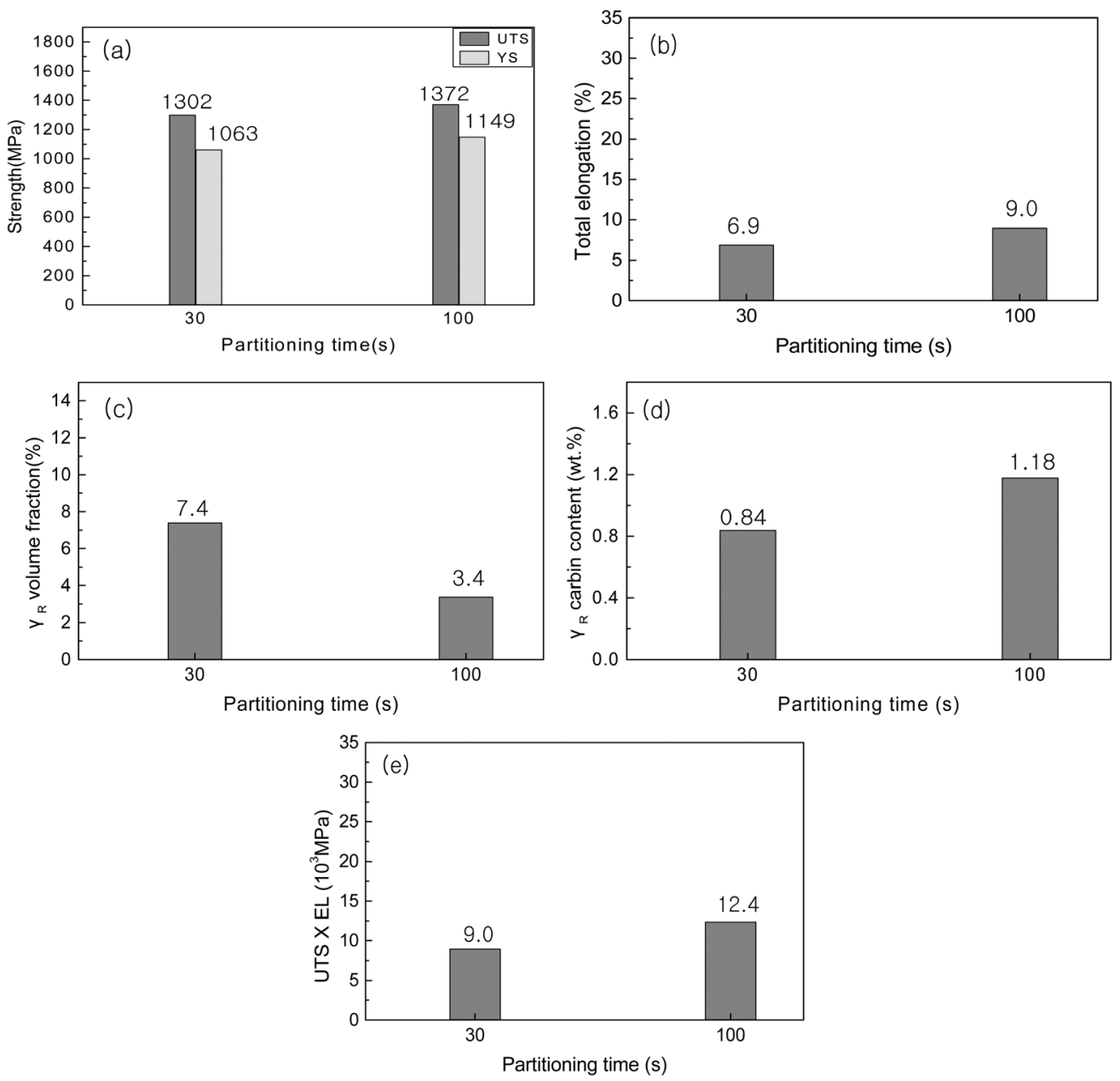

Fig. 7. Tensile properties, volume fraction of retained austenite, and carbon content in austenite for the Q\&P steels; (a) tensile strength and yield strength, (b) total elongation, (c) volume fraction of retained austenite, (d) stability of retained austenite, (e) UTS X EL combination.

$1000 \mathrm{Mpa}$ ) and ductility (total elongation $\approx 20 \%$ ). The elongation for Q\&P steel was smaller than that for TRIP steel. This was because the TRIP steel has ferrite phase and the ferrite influence the volume fraction, stability of prior austenite. The result, TRIP steel has more volume fraction and stability of the retained austenite than the Q\&P steel. If, the Q\&P steels will be produced by the intercritical annealing, volume fraction of ferrite increase and retained austenite is more stabilized. Consequently, tensile strength will be decreased and total elongation will be increased as the intercritical annealing comparing with this study. Therefore, the Q\&P steels by intercritical annealing will be satisfying the demand (tensile strength $>1000 \mathrm{Mpa}$, total elongation $\approx 20 \%$ ). In normal trend, TRIP effect decreases with the volume fraction of retained austenite, so decreasing the elongation. Nevertheless, the elongation increased in this study despite of the retained austenite decreased. Although the volume fraction of retained austenite decreased as the partitioning time increased from $30 \mathrm{~s}$ to $100 \mathrm{~s}$, the stability of the retained austenite increased (Fig. 7(d)). This was because carbon partitioning from supersaturated martensite to retained austenite was more significantly conducted for the longer period as the partitioning time was increased. Therefore, transformation of retained austenite to martensite could be retarded during the tensile test, probably increasing elongation. The reason of decreased volume fraction of retained austenite is not clearly defined in the study. The reasons include the probable interaction of competing reactions that have either carbide precipitation despite of $\mathrm{Si}$ added to suppress carbide precipitation or bainite transformation of the retained austenite during the partitioning treatment, or martensite transformation of the retained austenite on final quenching. 5) 


\section{Conclusions}

Strengthening mechanism was studied with respect to microstructural evolution for 0.2 carbon DP, TRIP and Q\&P steels and the following conclusions were drawn:

1. For DP steel, martensite increased as the intercritical annealing temperature increased, therefore increasing the tensile strength.

2. For TRIP steel, retained austenite was more stable and volume fraction of retained austenite was increased for the lower intercritical annealing temperature, so increasing the elongation.

3. For Q\&P steel, although the volume fraction of retained austenite for 100 s partitioning was lower than that for $30 \mathrm{~s}$ partitioning, retained austenite was more stabilized. Therefore, the elongation increased with the partitioning time.

4. Summarily martensite structures influenced the strength and ferrite structures influenced the ductility in DP steel. For TRIP steel, bainite dominated the level of strength and volume fraction of retained austenite regulated that of ductility. However, Q\&P steel had a complex mechanism of strengthening: martensite influenced strength, and volume fraction and/or stability of retained austenite controlled ductility.

\section{Acknowledgements}

This work was supported by a grant from POSCO technical research laboratories.

\section{References}

1. D. B. Im, C. G. Lee, S. J. Kim and I. M. Park, J. Kor. Inst. Met \& Mater., 38, 447 (2000).

2. H. J. Jun, S. H. Park, S. D. Choi and C. G. Park, Mater. Sci. Eng. A, 379, 204 (2004).

3. J. G. Speer, D. K. Matlock, B. C. DE Cooman and J.G. Schroth: Acta Metall. et Mater., 51, 2611 (2003).

4. D. K. Matlock, V. E. Brautigam and J. G. Speer, Materials Science Forum, 426, 1089 (2003).

5. S. C. Hong, J. C. Ahn, S. Y. Nam, S. J. Kim, H. C. Yang, J. G. Speer and D. K. Matlock, Met. \& Mater Int., 13, 439 (2007).

6. D. V. Edmond, K. H. F. C. Rizzo, B. C. De cooman, D. K. Matlock, J. G. Speer, Mater. Sci. Eng. A, 438, 25 (2006).

7. K. W. Andrews, J. Iron and Steel Inst., 203, 721(1965).

8. W. Steven and A. G. Haynes, J. Iron and Steel Inst. 183, 349 (1965).

9. R. O. Rocha, T. M. F. Melo, E. V. Perelom and D. B. Santos, Mater. Sci. Eng. (A) 391, 296-304 (2005).

10. C. G. Lee, S. J. Kim and S. H. Lee, J. Kor. Inst. Met \& Mater., 37, 1324-1331 (1999).

11. S. J. Kim and C. G. Lee, J. Kor. Inst. Met \& Mater., 37, 774-781 (1999).

12. Y. Tomita and K. Morioka, Materials Characterization, 38, 243 (1997).

13. B. D. Cullity, Elements of X-Ray Diffraction, p. 401-433, second ed. Addison-Wesley Publishing Co., Inc., Reading, MA 01867-3932, United States, (1978). 